\section{Modell, statistisches}

R.-D. Hilgers ${ }^{1}$, N. Heussen ${ }^{1}$ und S. Stanzel ${ }^{2}$

${ }^{1}$ Institut für Medizinische Statistik, Universitätsklinikum der RWTH Aachen, Aachen, Deutschland

${ }^{2}$ DKFZ Heidellberg, Heidelberg, Deutschland

Englischer Begriff statistical model

Definition Ein statistisches Modell beschreibt mathematisch-biologische Erscheinungen, in denen der Zufall eine wesentliche Rolle spielt.
Beschreibung Statistische Modelle werden z. B. im Rahmen der $\gg$ Regressionsanalyse oder der $\gg$ Varianzanalyse verwendet.

\section{Literatur}

Rasch D (1988) Biometrisches Wörterbuch. Verlag Harri Deutsch, Frankfurt am Main 